\title{
Factors determining the knowledge and prevention practice of healthcare workers towards COVID-19 in Amhara region, Ethiopia: a cross-sectional survey
}

Mulusew Andualem Asemahagn(1)

\begin{abstract}
Background: Healthcare workers (HWs) are at the highest risk of getting CIVID-19. This study aimed to assess factors determining the knowledge and prevention of HWs towards COVID-19 in the Amhara Region, Ethiopia.

Methods: A cross-sectional online survey was conducted among $442 \mathrm{HWs}$ using email and telegram addresses. The knowledge and practice of HWs were estimated using 16 knowledge and 11 practice questions. A multivariable logistic regression analysis was used on SPSS version 25 to identify factors related to the knowledge and prevention practice of HWs on COVID-19. Significance was determined at a $p$ value of $<0.05$ and association was described by using odds ratio at $95 \% \mathrm{Cl}$.

Results: Of 442 HWs, 398 (90\% response rate) responded to the online interview questionnaire. From 398 HWs, 231(58\%), 225(56\%), 207(53\%), and 191(48\%) were males, from rural area, aged $\geq 34$ years and nurses, respectively. About 279(70\%) HWs had good knowledge of COVID-19 followed by 247(62\%) good prevention practices. Age < 34 years $(A O R=2.14,95 \% \mathrm{Cl}=1.25-3.62)$, rural residence $(A O R=0.44,95 \% \mathrm{Cl}=0.26-0.70)$, access to infection prevention $(\mathrm{IP})$ training $(\mathrm{AOR}=2.4,95 \% \mathrm{Cl}=1.36-4.21)$, presence of $\mathrm{IP}$ guideline $(\mathrm{AOR}=2.82,95 \% \mathrm{Cl}=1.64-4.62)$, and using social media (AOR $=2.51,95 \% \mathrm{Cl}=1.42-4.53$ ) were factors of knowledge about COVID-19. Whereas, rural residence (AOR $=0.45,95 \% \mathrm{Cl}=0.31-0.75)$, facility type ( $\mathrm{AOR}=0.40,95 \% \mathrm{Cl}=0.28-0.89$ ), access to $\mathrm{IP}$ training (AOR $=2.32,95 \% \mathrm{Cl}=1.35-4.16)$, presence of IP guidelines ( $\mathrm{AOR}=2.10,95 \% \mathrm{Cl}=1.21-3.45)$, knowledge about COVID-19 $(A O R=2.98,95 \% \mathrm{Cl}=2.15-5.27)$, having chronic illnesses ( $\mathrm{AOR}=2.0,95 \% \mathrm{Cl}=1.15-3.75)$, lack of protective equipment (PPE) ( $A O R=0.42,95 \% \mathrm{Cl}=0.32-0.74)$, and high workload $(\mathrm{AOR}=0.40,95 \% \mathrm{Cl}=0.36-0.87$ ) were factors of COVID-19 prevention.

Conclusion: In this study, most of the HWs had good knowledge but had lower prevention practice of COVID-19. Socio-demographic and access to information sources were factors of knowledge on COVID-19. Similarly, residence, shortage of PPE, high workload, comorbidities, knowledge, and access to IP training and guideline were factors limiting prevention practices. Thus, a consistent supply of PPE and improving health workers' knowledge, making IP guidelines and information sources available, and managing chronic illnesses are crucial to prevent COVID-19 among HWs.
\end{abstract}

Keywords: COVID-19, Knowledge, Practice, Healthcare workers, Amhara region, Ethiopia

(c) The Author(s). 2020 Open Access This article is licensed under a Creative Commons Attribution 4.0 International License, which permits use, sharing, adaptation, distribution and reproduction in any medium or format, as long as you give appropriate credit to the original author(s) and the source, provide a link to the Creative Commons licence, and indicate if changes were made. The images or other third party material in this article are included in the article's Creative Commons licence, unless indicated otherwise in a credit line to the material. If material is not included in the article's Creative Commons licence and your intended use is not permitted by statutory regulation or exceeds the permitted use, you will need to obtain permission directly from the copyright holder. To view a copy of this licence, visit http://creativecommons.org/licenses/by/4.0/. 


\section{Background}

World Health Organization (WHO) declared that the coronavirus 2019 (COVID-19) as a pandemic on 11 March 2020, after 11 days of being declared as a public health emergency [1,2]. The COVID-19 has been reported as a continuing global epidemic since its first appearance in December 2019 from Wuhan City in China $[2,3]$. The COVID-19 is a zoonotic contagious disease that can transmit from animal to human and from human to human [4]. The major transmission route of COVID-19 is respiratory droplets produced from an infected person while sneezing and coughing. It is also transmitted by infected surfaces and objects since the virus can survive everywhere $[3,5,6]$. The COVID-19 has been characterized by wide clinical futures ranging from no symptoms to a severe form of respiratory illness [7-9]. The typical signs and symptoms of COVID-19 include respiratory symptoms, fever, cough and shortness of breath $[4,6-8,10]$. Occasionally, symptoms including headache, muscle pain, sore throat, loss of taste or smell, hemoptysis, and diarrhea were observed $[9,11]$.

The burden of COVID-19 has increased worldwide in terms of morbidity, mortality and economic crisis [2, 12, 13]. Globally, as of 27 July 2020, over 16249 165 confirmed cases of COVID-19 and 649208 deaths were reported [14]. Although the spread of COVID-19 is highest in Europe and America, it has been alarmingly increased in Africa [13, 15-17]. The situation might be serious in Sub-Saharan Africa due to high comorbidities (HIV, TB and malaria), poverty, and poor healthcare service quality and access to health facilities [13, 15]. As of 27 July 2020, 847,628 confirmed cases and 17,759 deaths were reported from Africa. The situation has no exception in Ethiopia, where the burden of COVID-19 has increased and about 13,968 confirmed cases and 223 deaths have been reported as of 27 July 2020 [14].

HWs are the highest risk groups for COVID-19 due to the nature of their occupation that exposed them to infectious people with COVID-19 every day. Several HWs have infected by COVID-19 and lost their lives globally due to job-related COVID-19 [12, 18, 19]. Unless special attention is given to make HWs and their working places safe, the system will lose many HWs and highly compromise the capacity of anti-COVID-19 and other infectious diseases worldwide. Unlike other people, the HWs have double sources of infection to COVID-19 from the community and working places. The main reasons for acquiring COVID-19 among HWs include long-time exposure, shortage and poor quality of PPE $[18,20]$. The HWs are typical infection sources of families, patients and the community [15, 20,21].

To date, much is known about the distribution, transmission, prevention, and supports, but no curative treatment or vaccine that has been recommended for the
COVID-19 [1, 6, 8, 22]. The WHO recommends the prevention of human-to-human transmission by avoiding close contacts, frequent handwashing with soap, and/or alcohol-based hand rubbing sanitizer, wearing PPE (facemask, shields and glove) and avoid going to crowded places [10, 22, 23]. Also, improving the knowledge and prevention practice of HWs and the community through regular updates about COVID-19 is crucial [10, 23]. If HWs have access to information sources, they will upgrade their knowledge and apply preventive devices to prevent COVID-19 and give appropriate care to patients, families and the community $[15,18,23]$.

Recent literature on infection prevention (IP) practice of HWs in Ethiopia also depicted the presence of relatively better knowledge and attitude on infection prevention practices. The prevention practice of most HWs however did not go with their knowledge and attitude levels [21, 24-26]. This might be related to less attention to IP and work safety, absence and poor quality of PPE, negligence of HWs and less comfortable working offices. Also, there is no recent evidence on the existing prevention practice of HWs towards COVID-19 in Ethiopia, in particular, the Amhara Region. Thus, this study aimed to assess the prevention practice and associated factors of HWs towards COVID-19 in the Amhara Region, Ethiopia. This might play a vital role in preventing COVID-19 among HWs and stop the spread of infections to the community.

\section{Methods}

\section{Study design and settings}

Due to the country's lockdown for COVID-19 prevention, an online cross-sectional study was conducted between April and May 2020 among HWs working in public hospitals and health centers (HCs) of the Amhara Region, Ethiopia. Amhara Region is the second-largest region in Ethiopia. Amhara Region is divided into 10 administrative zones (third administration level in Ethiopia) and 3 town administrations. The capital city of the region is Bahir Dar city, where the regional health bureau and Amhara regional Public Health Institute are located. Based on the 2018 regional health bureau report, the region has about 4267 public health facilities (77 hospitals, $848 \mathrm{HCs}$, and 3342 health posts) to offer healthcare services to a total population of $21,841,999: 4$, 089,997 urban and 17,752,002 rural. A total of 38,000 HWs with different professional disciplines are working in those healthcare facilities [27].

\section{Sample size determination and sampling procedures}

The sample size of the study participants (442) was determined using a single population proportion formula based on the following assumption: $50 \%$ proportion to prevention practice among HWs since no previous study 
on COVID-19 prevention practice, 95\% confidence level, $5 \%$ margin of error, and $15 \%$ non-response rate by considering high delayed responses and non-respondents since it is an online survey. The study participants were selected randomly from the alphabetical list of all HWs in the Amhara Regional Health Bureau using the Stat Trek Random Number Generator tool [28]. Then, the investigator addressed sampled HWs through the regional health bureau, zonal health departments and human resource managers of health facilities. Based on the selected HWs, 70 health facilities (10 hospitals and 60 health centers) were study sites.

\section{Data collection tools and techniques}

Data were collected online using a structured questionnaire and using email and telegram services of HWs working in different units of hospitals and HCs. The questionnaire was designed using Google Forms (via docs. google.com/forms) by referring to former studies on IP and the WHO IP guidelines [15, 16, 18, 23, 26, 29]. The questionnaire consists of questions related to demographics, information sources, risk assessment, knowledge and practice towards the COVID-19. The clarity, appropriateness and redundancy of questions were revised based on findings from the pretest. HWs had been informed well about the purpose of the study, data confidentiality and data collection procedures. After they became clear about the study and its procedure, the investigator asked each participant for consent by sending the consent form before data collection. After collecting the signed consent form from each health worker, the investigator sent the Google form link (questionnaire) to HWs for data collection. Data were collected from 5 April to 25 May 2020. In this study, HWs are health professionals who had primary contact with patients during clinical examination and biological specimen collection that include physicians, nurses, health officers and laboratory technicians/technologists.

\section{Data quality assurance}

The questionnaire was designed with ease of use and pretested before data collection. Cronbach alpha was used to check the validity of the tool and the value of ' $\alpha$ ' was 8.92. HWs had been informed of detailed information with practice on how to complete and sent the questionnaire. Duplication of responses was controlled by restricting to one response. The incompleteness of responses was reduced by making each "“"required" to pass to the next question.

\section{Data management and analysis}

The collected data were checked for completeness and exported to the MS-excel format. The excel data were then exported to SPSS version 25 for editing and analysis. There were 16 knowledge questions with "yes $=1$ " or "no $=0$ " responses to give values ranging from 0 to 16. A health worker who scored $80 \%$ and above was grouped as having "good knowledge" and who scored below $80 \%$ was grouped as having "poor knowledge." On the other hand, there were 11 practice-related questions responded as "always $=1$ " and "rarely $=0$ " with total values ranging from 0 to 11 . A health worker who scored $75 \%$ and above was grouped as "good practitioner" and who scored below 75\% was grouped as "poor practitioner" [15]. The reason for using a $75 \%$ cut off value for practice was by considering the seriousness of the COVID-19, and the study participants are health workers to whom the prevention practice is mandatory to keep themselves families safe from COVID-19 and be a role model to their patients and the rest of the community.

Descriptive statistics including mean, median, standard deviation, range, cross-tabulations and proportions were computed. The model fitness was checked by the Hosmer-Lemeshow goodness of fit test before the regression analysis. Bivariate and multivariable logistic regression analyses were conducted to identify factors associated with HWs' knowledge and practice towards COVID-19. Variables with a $p$ value of $<0.2$ in the bivariate analysis were used to fit the multivariable model to control the confounding effect. Variables with a $p$ value of $<0.05$ in the multivariable model were considered as significant factors. Associations between study and outcome variables were described using the odds ratio at $95 \% \mathrm{CI}$.

\section{Results}

Socio-demographic and risk assessment of health workers Of the total $442 \mathrm{HWs}, 398(90 \%$ response rate) responded to the online survey interview and 231(58\%) were males. Over half, 207(53\%) HWs, aged $\geq 34$ years (mean age $=34 \pm 5$ years). Over half, 225(56\%) HWs, were working in rural health facilities. Nearly half, 191(48\%), of the HWs were nurses and 243 (61\%) were from HCs. Only $88(22 \%)$ HWs had histories of domestic travel in recent times. A small number of HWs, 60 (15\%), 48 (12\%) and 179 (45\%), had histories of chronic illness, smoking and taking alcohol in any amount, respectively. A limited number of HWs, 151 (38\%) took training in IP in recent times. A significant number of HWs, 239 (60\%) and 259 (65\%), used social media and television and or radio as information sources about COVID-19, respectively. Over half, 207(52\%), of the HWs noted the presence of adequate PPE in their health facilities. However, only 159 (40\%) HWS stated the presence of IP guidelines in their working areas. Less than half, 167(42\%), of the HWs reported as high workload prevented them from practicing COVID-19-prevention (Table 1). 
Table 1 Socio-demographic characteristics of HWs in the Amhara Region, Ethiopia, 2020

\begin{tabular}{|c|c|c|}
\hline Variable & Response & Frequency (\%) \\
\hline \multirow[t]{2}{*}{ Age in years } & $<34$ & $187(47.0)$ \\
\hline & $\geq 34$ & $211(53.0)$ \\
\hline \multirow[t]{2}{*}{ Sex } & Male & $231(58.0)$ \\
\hline & Female & $167(42.0)$ \\
\hline \multirow[t]{5}{*}{ Profession } & Physician & $32(8.0)$ \\
\hline & Nurse & $191(48.0)$ \\
\hline & Health officer & $60(15.0)$ \\
\hline & Midwifery & $64(16.0)$ \\
\hline & Laboratory & $51(13.0)$ \\
\hline \multirow[t]{2}{*}{ Residence } & Rural & $225(56.0)$ \\
\hline & Urban & $173(44.0)$ \\
\hline \multirow[t]{3}{*}{ Marital status } & Single & $119(30.0)$ \\
\hline & Married & $271(68.0)$ \\
\hline & Divorced & $8(2.0)$ \\
\hline \multirow[t]{2}{*}{ Family size } & $\leq 4$ & $287(72.0)$ \\
\hline & $>4$ & $111(28.0)$ \\
\hline \multirow[t]{2}{*}{ Working experience in years } & $\leq 5$ & $159(40.0)$ \\
\hline & $>5$ & $239(60.0)$ \\
\hline \multirow[t]{2}{*}{ HWs' health facilities } & $\begin{array}{l}\text { Health } \\
\text { centers (HCs) }\end{array}$ & $243(61.0)$ \\
\hline & Hospital & $155(39.0)$ \\
\hline \multirow[t]{2}{*}{ Trained in IP within a year } & Yes & $151(38.0)$ \\
\hline & No & $247(62.0)$ \\
\hline \multirow{2}{*}{$\begin{array}{l}\text { Have travel history in } \\
\text { recent times }\end{array}$} & Yes & $40(10.0)$ \\
\hline & No & $358(90.0)$ \\
\hline \multirow[t]{2}{*}{ Have chronic illnesses } & Yes & $60(15.0)$ \\
\hline & No & $338(85.0)$ \\
\hline \multirow{2}{*}{$\begin{array}{l}\text { Smoke cigarette in } \\
\text { any amount }\end{array}$} & Yes & $48(12.0)$ \\
\hline & No & $350(82.0)$ \\
\hline \multirow{2}{*}{$\begin{array}{l}\text { Drinking alcohol in } \\
\text { any amount }\end{array}$} & Yes & $179(45.0)$ \\
\hline & No & $219(55.0)$ \\
\hline \multirow{2}{*}{$\begin{array}{l}\text { Use social media as an } \\
\text { information source }\end{array}$} & Yes & $239(60.0)$ \\
\hline & No & $159(40.0)$ \\
\hline \multirow{2}{*}{$\begin{array}{l}\text { Television /radio is my } \\
\text { information source }\end{array}$} & Yes & $259(65.0)$ \\
\hline & No & $139(35.0)$ \\
\hline \multirow{2}{*}{$\begin{array}{l}\text { Adequate access to PPE } \\
\text { in health facilities }\end{array}$} & Yes & $207(52.0)$ \\
\hline & No & $191(48.0)$ \\
\hline \multirow{2}{*}{$\begin{array}{l}\text { Adequate access to } \\
\text { disinfectants }\end{array}$} & Yes & $112(28.0)$ \\
\hline & No & $286(72.0)$ \\
\hline \multirow{2}{*}{$\begin{array}{l}\text { There is IP guideline in } \\
\text { health facilities }\end{array}$} & Yes & $159(40.0)$ \\
\hline & No & $239(60.0)$ \\
\hline \multirow{2}{*}{$\begin{array}{l}\text { High workload lowered } \\
\text { my IP practices }\end{array}$} & Yes & $167(42.0)$ \\
\hline & No & $231(58.0)$ \\
\hline \multirow{2}{*}{$\begin{array}{l}\text { Discomfort while using PPE } \\
\text { lower my utilization }\end{array}$} & Yes & $207(52.0)$ \\
\hline & No & $191(48.0)$ \\
\hline
\end{tabular}

Knowledge of health workers about COVID-19 infection Of the surveyed HWs, 279(70\%) had demonstrated good knowledge about COVID-19. Most, 351(88\%) and $339(85 \%)$ of the HWs reported that COVID-19 is a viral disease and has no effective treatment or vaccine yet, respectively. Over two-thirds, 275(69\%) HWs stated as animals and humans are the primary sources of infection to COVID-19. Also, 263(66\%) HWs mentioned respiratory droplets and close contact are the main transmission routes of COVID-19. Nearly half, 191(48\%) HWs, also reported contaminated objects and surfaces as potential transmission routes. The majority, 338 (85\%) HWs identified chronically ill people are at the highest risk of COVID-19. In addition, 303(76\%) HWs pointed out that fever, dry cough and shortness of breath are typical signs and symptoms of people who had COVID-19. Also, $318(80 \%)$ and $315(79 \%)$ HWs knew that frequent handwashing and social distance are important to prevent COVID-19. Moreover, $85 \%$ and $80 \%$ HWs mentioned that COVID-19 had no cure treatment or vaccine, and isolation of suspected people is crucial to prevent COVID-19, respectively (Fig. 1).

\section{The COVID-19 prevention practices of health workers}

In this study, 247(62\%) HWs had good prevention practices towards COVID-19. The majority, 326(82\%) and $318(80 \%)$ HWs regularly practice handwashing or alcohol-based sanitizer and wearing facemasks, respectively. Similarly, 271(68\%) HWs frequently cover their mouth and nose while sneezing and 231(58\%) of them disposed of the covering materials they used during sneezing properly to the dustbin. Also, 231(58\%), 223(56\%), and 215(54\%) HWs avoid handshaking/shoulder kissing/touching mouth/nose/eye with unwashed hands and go to the crowded places, respectively. Only 116(29\%) HWs always use disinfectants (Fig. 2).

Factors associated with HWs' knowledge about COVID-19 Based on the multivariable logistic regression model, HWs < 34 years of age were double times to have good knowledge about COVID-19 compared to people aged 34 years and above $(\mathrm{AOR}=2.14,95 \% \mathrm{CI}=1.25-3.62)$. HWs from rural health facilities were $56 \%$ times less likely to have good knowledge about COVID-19 compared to the counterpart HWs $(\mathrm{AOR}=0.44,95 \% \mathrm{CI}=$ 0.26-0.70). Similarly, the odds of having good knowledge among HWs who got training in IP was over twice than the counterpart HWs $(\mathrm{AOR}=2.4,95 \% \mathrm{CI}=1.36-4.21)$. HWs who used social media as information sources were 2.51 times knowledgeable compared to HWs who did not access information using social media $(\mathrm{AOR}=$ 2.51, 95\% CI $=1.42-4.53)$. The odds of having good knowledge among HWs who had access to IP guideline 


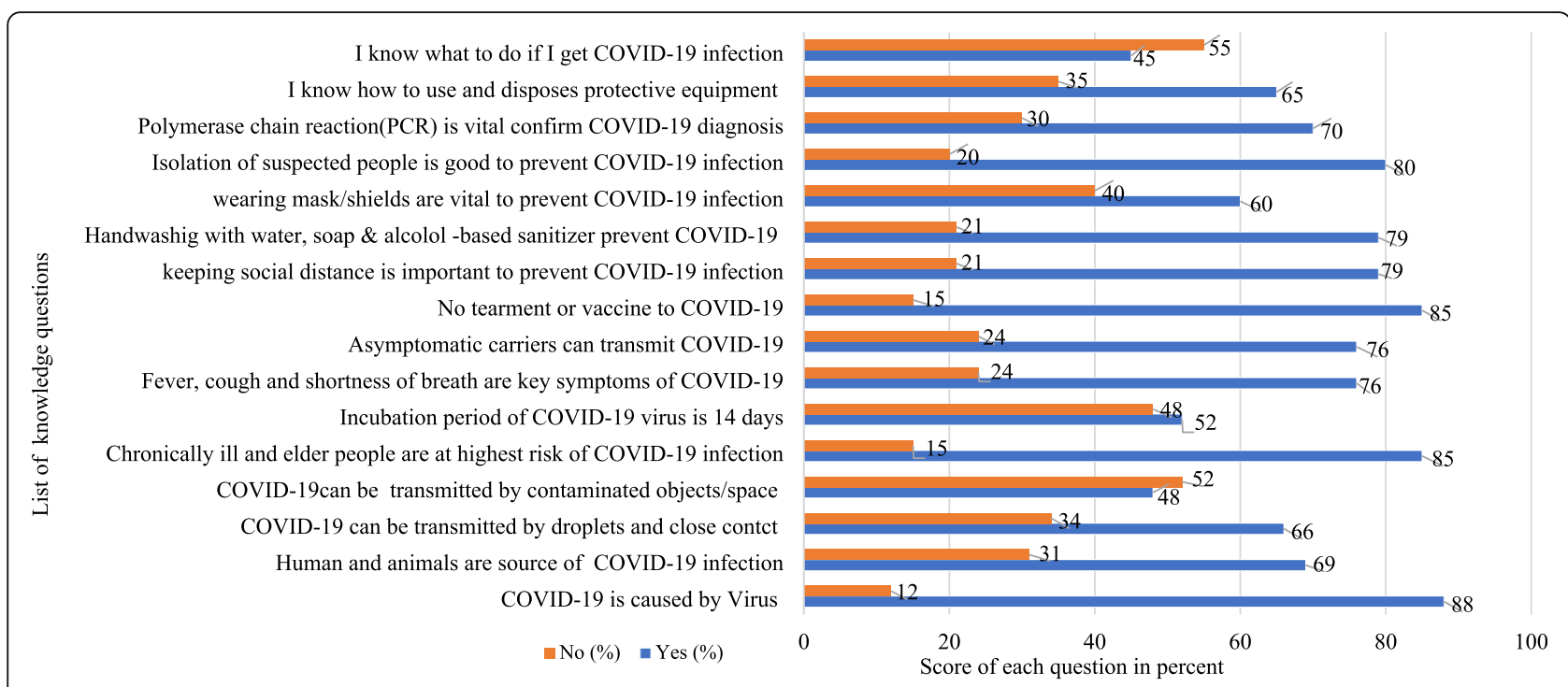

Fig. 1 Knowledge of HWs about COVID-19 in the Amhara region of Ethiopia, 2020

was nearly three times more compared to the counterpart HWs $(\mathrm{AOR}=2.82,95 \% \mathrm{CI}=1.64-4.62)($ Table 2$)$.

\section{Factors affecting COVID-19 prevention among health workers}

HWs from rural areas were 55\% times less likely to have good COVID-19 prevention practices than their counterpart HWs (AOR 0.45, 95\% CI $=0.31-0.75$ ). The odds of having good COVID-19 prevention was twice among HWs who took training in IP and who had access to IP guideline $(\mathrm{AOR}=2.32,95 \% \mathrm{CI}=1.35-4.16 ; \mathrm{AOR}=$ $2.10,95 \% \mathrm{CI}=1.21-3.45)$, respectively. Also, HWs who had good knowledge of COVID-19 were triple times to prevent it compared to HWs who had poor knowledge (AOR $=2.98,95 \% \mathrm{CI}=2.15-5.27)$. The odds of having good preventive practice were twice among HWs who had chronic illnesses than the counterpart HWs. Moreover, HWs who had limited access to PPE, high workload, and HWs from health centers were $58 \%, 60 \%$, and $60 \%$ times less likely to have good COVID-19 prevention practice, respectively (Table 3 ).

\section{Discussion}

This study assessed the knowledge and practice of HWs concerning COVID-19 and identified factors associated with knowledge and infection control practices of HWs about COVID-19. The outputs of this study are crucial to HWs, health facilities, health offices and researchers to halt the spread of COVID-19 and fill literature gap $[20,23,30]$. Because HWs are at the front line in the COVID-19 prevention system, they have the highest risk of acquiring the infection and spreading it to their families and the community $[16,24,25]$. In addition, HWs have faced psychological stress and social stigma because of COVID-19 and their occupation [12, 18, 31].

This study depicted that over two-thirds (70\%) HWs had good knowledge about COVID-19. This finding is higher compared to findings from Bale Zone [24] and Addis Ababa [26], Ethiopia where the knowledge of HWs about IP practices in health facilities was $55.4 \%$ and $38.6 \%$, respectively. This difference might be related to variations in the study period, study area coverage and the nature of the topic. This study included large area coverage (region level), whereas the former studies were at zonal levels (administrations within a region). When we see the time and nature of the topic, our study is knowledge about COVID-19 which is a timely issue but the former studies were about knowledge on overall IP practice and work safety of health facilities. Thus, COVID-19 has gotten global attention and advertised via social and mass media to inform the population at large.

On the other hand, the current knowledge level was found to be lower compared to former study findings of COVID-19 and IP practices. It was found lower than 81.6\% from Gondar University Hospital [25], 86.4\% from Dessie Hospital [32], 84\% from Bahir Dar City [33], and 84.6\% from Debremarkos Town [34]. All the former studies were about knowledge of HWs on the general IP practices but this study is HWs' knowledge about COVID-19. The time of the study and studied topic might also contribute to this variation. This study is about HWs' knowledge of COVID-19 that is not well known and fully practiced in rural health facilities due to no diagnostic and treatment services. This might lower the HWs' knowledge about COVID-19. 


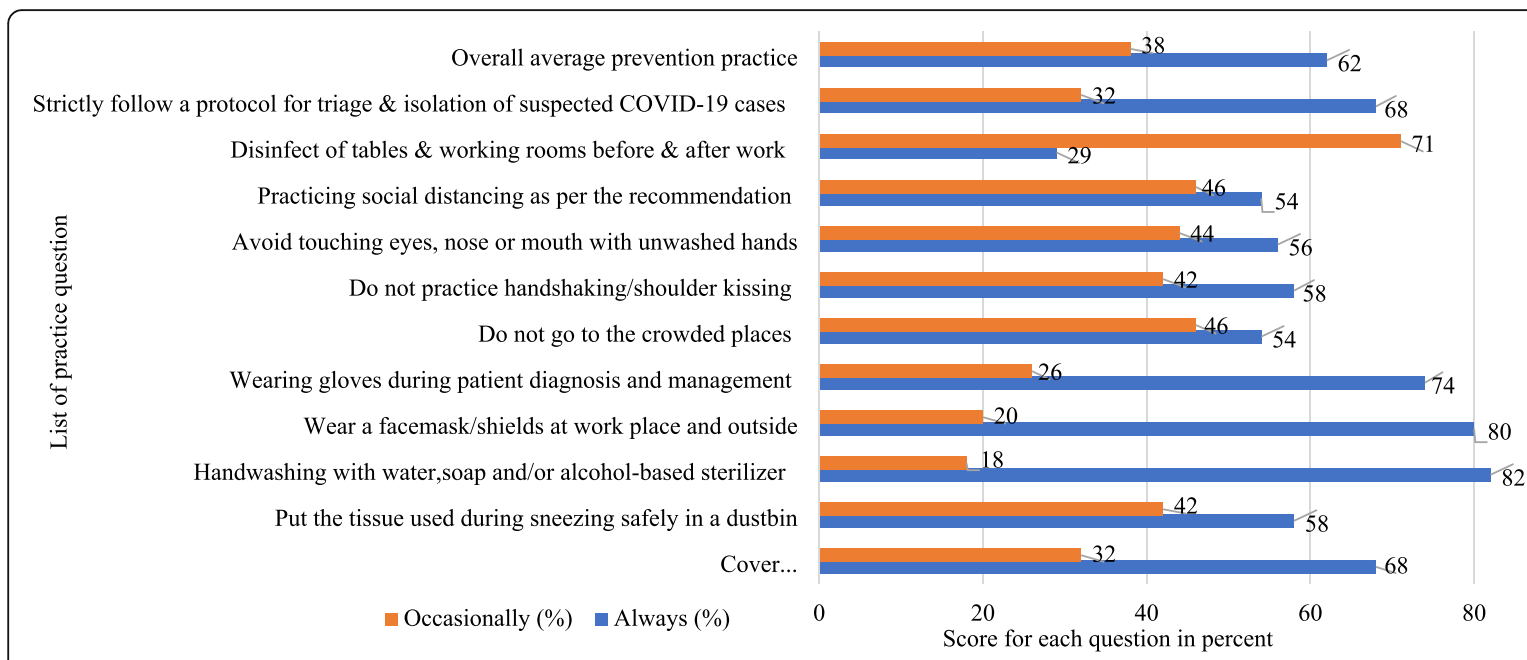

100

Fig. 2 The prevention practice of HWs towads COVID-19 in the Amhara region of Ethiopia, 2020

Moreover, this finding was found lower than $82.4 \%$ knowledge on COVID-19 from Uganda [15], 78.6\% from Nigeria [16], 93.2\% from Pakistan [30], 89\% and 90\% from China [35, 36], and 80\% from the USA [37]. This variation might be caused by differences in the study area and population, geographic coverage, and number and type of questions used. The current study used large area coverage where most participants were from rural areas that had limited access to information sources, IP practices and COVID-19 diagnosis and support services than the situation in the abroad that included urban health facilities with better access to information sources, IP facilities and COVID-19 prevention practices.

In this study, HWs had $80-85 \%$ scores for the causative agent (virus), knowing highest risk population groups, no treatment/vaccine, and prevention mechanisms (isolation, social distance, and handwashing of COVID-19). This is in line with findings from the former studies on COVID-19 [30, 35-37]. HWs however had lower scores $(45-76 \%)$ for questions related to transmission routes of COVID-19. This is a critical issue that needs special attention from the concerned offices because prevention might be in place if HWs knew well the transmission routes. The low scores might be due to including more HWs from rural health facilities that had limited access to information sources and preventive devices $[13,38,39]$.

This study demonstrated the main information sources to HWs where $60 \%$ and $65 \%$ accessed information about COVID-19 from TV and social media (Facebook, Youtube, Telegram and Twitter), respectively. This is because of easily accessible to most HWs at home and working areas through the mobile internet. This was different from the situation in Saudi Arabia where most of the HWs accessed information about COVID-19 and other infectious diseases form the website of the
Ministry of Health [40]. This implied that the Ethiopian Government and the Ministry of Health need to use social media and television to disseminate information to HWs.

This study indicated that the knowledge and practice of HWs were not matching. Only $62 \%$ of HWs had good prevention practices towards COVID-19. This implied that more HWs who had good knowledge had poor prevention practices. It might be due to the absence and /or poor quality of PPE and reservation from using PPE due to some discomforts. Thus, priority needs to be given to improve prevention practices parallel to awareness creation and making PPE available. Handwashing and wearing of facemasks and glove were frequently practiced and had up to $82 \%$ of scores. Differently, only $29 \%$ of HWs always disinfect tables, chairs, other materials and their rooms before and after work. It was incomparable with study findings from Nigeria [16] where the use of disinfectants among HWs was $83.9 \%$. This might be either because of no access to disinfectants or less attention to the values of disinfectants in Ethiopia.

The overall practice score was almost consistent with study findings from Addis Ababa [26] and Wolita Sodo [41], Ethiopia, where the infection prevention practices of HWs were $66.1 \%$ and $60.5 \%$, respectively. On the other hand, it was higher than $36.8 \%$ from Bale zone [24], 57.4\% from Gondar University Hospital [25], 23\% from Dessie Town [32], 54.2\% from Bahir Dar City [33], $56.8 \%$ from Nigeria [16] and 57.3\% from Debremarkos Town [34]. This difference might be related to variations in the study period, study topic, presence of IP guideline and PPE materials, access to IP training and commitment of HWs [15, 24, 25].

In contrast, this finding was lower than study findings from Uganda [15], China [35] and Pakistan [30] in which $74 \%, 89.7 \%$ and $88.7 \%$ of HWs practiced COVID-19 
Table 2 Factors affecting HWs' knowledge of COBID-19 in the Amhara Region, Ethiopia, 2020

\begin{tabular}{|c|c|c|c|c|}
\hline \multirow[t]{2}{*}{ Variables } & \multicolumn{2}{|c|}{$\begin{array}{l}\text { Knowledge on } \\
\text { COVID-19 }\end{array}$} & \multirow[t]{2}{*}{ COR $(95 \% \mathrm{Cl})$} & \multirow[t]{2}{*}{ AOR $(95 \% \mathrm{Cl})$} \\
\hline & Good & Poor & & \\
\hline \multicolumn{5}{|l|}{ Age } \\
\hline$<34$ & $150(37.7)$ & $37(9.3)$ & $2.58(1.64-4.06)$ & $2.14(1.25-3.62)$ \\
\hline$\geq 34$ & $129(32.4)$ & $82(20.6)$ & 1 & 1 \\
\hline \multicolumn{5}{|l|}{ Sex } \\
\hline Male & $156(39.2)$ & 75 (18.8) & $0.74(0.48-1.16)$ & $0.60(0.25-1.06)$ \\
\hline Female & $123(31.0)$ & $44(11.0)$ & 1 & 1 \\
\hline \multicolumn{5}{|l|}{ Residence } \\
\hline Rural & $140(35.1)$ & 85 (21.4) & $0.41(0.25-0.64)$ & $0.44(0.26-0.70)$ \\
\hline Urban & $139(35.0)$ & $34(8.5)$ & 1 & 1 \\
\hline \multicolumn{5}{|l|}{ Family size } \\
\hline$\leq 4$ & $197(49.5)$ & $90(22.6)$ & $0.77(0.47-1.27)$ & $0.56(0.24-1.15)$ \\
\hline$>4$ & $82(20.6)$ & $29(7.3)$ & 1 & 1 \\
\hline \multicolumn{5}{|c|}{ Working experience } \\
\hline$\leq 5$ years & $115(29.0)$ & $44(11.0)$ & $1.20(0.77-1.86)$ & $0.86(0.46-1.24)$ \\
\hline$>5$ years & $164(41.2)$ & 75 (18.8) & 1 & 1 \\
\hline \multicolumn{5}{|c|}{ HWs' health facility } \\
\hline Health center & $154(38.7)$ & 89 (22.3) & $1.15(0.76-1.75)$ & $0.85(0.52-1.45)$ \\
\hline Hospital & $93(23.4)$ & $62(15.6)$ & 1 & 1 \\
\hline \multicolumn{5}{|c|}{ Trained in infection prevention } \\
\hline Yes & $117(29.4)$ & $34(8.5)$ & $1.81(1.14-2.87)$ & $2.4(1.36-4.21)$ \\
\hline No & $162(40.7)$ & $85(21.4)$ & 1 & 1 \\
\hline \multicolumn{5}{|c|}{ TV is my information source } \\
\hline Yes & $169(42.5)$ & $70(17.6)$ & $1.10(0.69-1.67)$ & $0.78(0.35-1.35)$ \\
\hline No & $110(27.6)$ & $49(12.3)$ & 1 & 1 \\
\hline \multicolumn{5}{|c|}{ Got information from social media } \\
\hline Yes & $194(48.7)$ & $65(16.3)$ & $1.90(1.22-2.95)$ & $2.51(1.42-4.53)$ \\
\hline No & $85(21.4)$ & $54(13.6)$ & & 1 \\
\hline \multicolumn{5}{|c|}{ Presence of IP guideline } \\
\hline Yes & $132(33.0)$ & $27(7.0)$ & $3.1(1.88-4.99)$ & $2.82(1.64-4.62)$ \\
\hline No & $147(37.0)$ & $92(23.0)$ & & 1 \\
\hline \multicolumn{5}{|l|}{ High workload } \\
\hline Yes & $112(28.0)$ & $55(14.0)$ & $0.78(0.51-1.20)$ & $0.82(0.53-1.14)$ \\
\hline No & $167(42.0)$ & $64(16.0)$ & 1 & 1 \\
\hline
\end{tabular}

prevention strategies, respectively. This inconsistency might be related to variations in the geographic area, the incidence of COVID-19, availability of PPE, IP policies among countries, training access, information sources and awareness levels of HWs [24, 42].

Based on the analysis, the rural residence was found to have an inverse association with the knowledge and practice of HWs towards COVID-19. HWs from rural health facilities had less likely odds to have good knowledge and practice (Tables 2 and 3). This might be related to limited access to health information sources such as guidelines, training, and the internet to update themselves. There is also limited access to PPE, washing facilities, isolation rooms and disinfectants [24, 32, 42]. Also, from personal observation, the rural community had less awareness of COVID-19. All these might lead them to have limited knowledge and prevention practices about COVID-19 compared to HWs in urban settings.

Based on the multivariable model, being trained in IP and having IP guidelines were positively associated with the knowledge and prevention practice of HWs towards COVID-19. This was supported by findings from formers studies $[15,25,26,42]$ that reported training was a predictor to improve the knowledge and practice of IP among HWs. The primary aim of training in IP is to improve the knowledge of HWs about preventive mechanisms and how to apply them to prevent infections at working places and accessing the required IP equipment and guidelines. If HWs have IP guidelines and know well how to prevent and the risk of not practicing preventive strategies, they will apply all the possible preventive mechanisms to avoid infections. Most of the time, good knowledge from training and IP guidelines is a predisposing factor for having better infection prevention practices $[24,26,30]$.

HWs who used social media as information sources had over double times odd to have good knowledge about COVID-19 compared to the counterpart HWs. This result was supported by former study findings from China [35, 36] and Iran [43] in which the main source of knowledge about infection prevention was using social media. It might be linked to ease of use and access the service using everywhere using mobile internet and social media (Facebook, Youtube, Twitter and others) are have been used worldwide. So, everybody can update his knowledge and information demand using these media. The informants (government and ministry of health) need to assess the media preference of HWs and the community to offer information concerning the COVID19 and other health-related information effectively.

In this study, health facility type was found to be statistically associated with infection prevention practices of HWs. HWs who worked in HCs were $60 \%$ times less likely to practice COVID-19 prevention than hospital health workers. This was supported by previous studies $[16,24,33,42]$ where HWs working in urban and advanced hospitals had better infection prevention practices than the rural and primary care health facilities. This might be attributed to the availability of better training, PPE, IP guidelines, personal commitments and follow-up, and advanced healthcare procedures (surgery) that lead to infection. There might also more COVID-19 
Table 3 Factors of COVID-19 prevention among HWs in Amhara Region, Ethiopia, 2020

\begin{tabular}{|c|c|c|c|c|}
\hline \multirow[t]{2}{*}{ Variables } & \multicolumn{2}{|c|}{ HWs practice } & \multirow[t]{2}{*}{ COR $(95 \% \mathrm{Cl})$} & \multirow[t]{2}{*}{ AOR $(95 \% \mathrm{Cl})$} \\
\hline & Good & Poor & & \\
\hline \multicolumn{5}{|l|}{ Age } \\
\hline$<34$ & $110(27.6)$ & $77(19.4)$ & $0.77(0.51-1.16)$ & $0.68(0.37-1.13)$ \\
\hline$\geq 34$ & $137(34.4)$ & $74(18.6)$ & 1 & 1 \\
\hline \multicolumn{5}{|l|}{ Sex } \\
\hline Male & $138(34.7)$ & $93(23.4)$ & $0.79(0.52-1.93)$ & $1.3(0.82-2.61)$ \\
\hline Female & $109(27.4)$ & $58(14.6)$ & 1 & 1 \\
\hline \multicolumn{5}{|l|}{ Residence } \\
\hline Rural & $120(30.2)$ & $105(26.4)$ & $0.41(0.27-0.63)$ & $0.45(0.31-0.75)$ \\
\hline Urban & $127(32.0)$ & $46(11.6)$ & 1 & 1 \\
\hline \multicolumn{5}{|c|}{ Working experience } \\
\hline$\leq 5$ years & $101(25.4)$ & $58(14.6)$ & $1.12(0.73-1.68)$ & $0.89(0.41-1.40)$ \\
\hline$>5$ years & $146(36.7)$ & $93(23.4)$ & 1 & 1 \\
\hline \multicolumn{5}{|c|}{ Health facility of HWs } \\
\hline Health center & $128(32.0)$ & $116(29.0)$ & $0.32(0.21-0.51)$ & $0.40(0.28-0.89)$ \\
\hline Hospital & $119(30.0)$ & $35(9.0)$ & 1 & 1 \\
\hline \multicolumn{5}{|l|}{ Trained in IP } \\
\hline Yes & $115(29.0)$ & $36(9.0)$ & $2.78(1.77-4.37)$ & $2.32(1.35-4.16)$ \\
\hline No & $132(33.0)$ & $115(29.0)$ & 1 & 1 \\
\hline \multicolumn{5}{|c|}{ Knowledge about COVID-19 } \\
\hline Good & $198(49.7)$ & $81(20.4)$ & $3.49(2.23-5.46)$ & $2.98(2.15-5.27$ \\
\hline Poor & $49(12.3)$ & $70(17.6)$ & 1 & 1 \\
\hline \multicolumn{5}{|c|}{ Use TV as information source } \\
\hline Yes & $146(36.7)$ & $93(23.4)$ & $0.85(0.56-1.29)$ & $1.31(0.85-2.78)$ \\
\hline No & $103(25.9)$ & $56(14.0)$ & 1 & 1 \\
\hline \multicolumn{5}{|c|}{ Presence of IP guideline } \\
\hline Yes & $117(29.4)$ & $42(10.6)$ & $2.34(1.51-3.61)$ & $2.10(1.21-3.45)$ \\
\hline No & $130(32.6)$ & $109(27.4)$ & 1 & 1 \\
\hline \multicolumn{5}{|c|}{ Have chronic illnesses } \\
\hline Yes & $46(11.6)$ & $14(3.5)$ & $2.24(1.19-4.23)$ & $2.0(1.15-3.75)$ \\
\hline No & $201(50.5)$ & $137(34.4)$ & 1 & 1 \\
\hline \multicolumn{5}{|l|}{ Smoke cigarette } \\
\hline Yes & $28(9.5)$ & $20(2.5)$ & $0.84(0.45-1.55)$ & $0.58(0.24-1.31)$ \\
\hline No & $219(52.5)$ & $131(35.5)$ & 1 & 1 \\
\hline \multicolumn{5}{|l|}{ Drinking alcohol } \\
\hline Yes & $130(32.7)$ & $49(12.3)$ & $0.84(0.53-1.30)$ & $0.64(0.38-1.26)$ \\
\hline No & $167(42.0)$ & $52(13.0)$ & 1 & 1 \\
\hline \multicolumn{5}{|l|}{ Shortage of PPE } \\
\hline Yes & $93(23.4)$ & $98(24.6)$ & $0.33(0.21-0.50)$ & $0.42(0.32-0.74)$ \\
\hline No & $154(38.7)$ & $53(13.3)$ & 1 & 1 \\
\hline \multicolumn{5}{|c|}{ Shortage of disinfectants } \\
\hline Yes & $130(32.7)$ & $156(39.2)$ & $0.80(0.52-1.25)$ & $0.60(0.32-1.20)$ \\
\hline No & $57(14.3)$ & 55 (13.8) & 1 & 1 \\
\hline
\end{tabular}


Table 3 Factors of COVID-19 prevention among HWs in Amhara Region, Ethiopia, 2020 (Continued)

\begin{tabular}{|c|c|c|c|c|}
\hline \multirow[t]{2}{*}{ Variables } & \multicolumn{2}{|c|}{ HWs practice } & \multirow[t]{2}{*}{ COR $(95 \% \mathrm{Cl})$} & \multirow[t]{2}{*}{ AOR $(95 \% \mathrm{Cl})$} \\
\hline & Good & Poor & & \\
\hline \multicolumn{5}{|c|}{ High workload } \\
\hline Yes & $77(19.4)$ & $90(22.6)$ & $0.31(0.20-0.67)$ & $0.40(0.36-0.87)$ \\
\hline No & $170(42.7)$ & $61(15.3)$ & 1 & 1 \\
\hline \multicolumn{5}{|c|}{ Discomfort from wearing PPE } \\
\hline Yes & $125(31.4)$ & $82(20.6)$ & $0.86(0.57-1.30)$ & $0.62(0.36-1.21)$ \\
\hline No & $122(30.7)$ & $69(17.3)$ & 1 & 1 \\
\hline
\end{tabular}

suspected cases in hospitals and referral places. All these mandated the hospitals to have relatively better awareness and IP practices among HWs in hospitals.

Moreover, HWs who had good knowledge about COVID-19 were triple times more to have good IP practices. The former studies reported similar findings that good knowledge of HWS about IP was determinant to have good IP practice $[15,26,30,33,41]$. It is true that if HWs have better knowledge about IP and its importance, they will possibly apply it in their working areas and make themselves safe from acquiring work-related infections. This indicates that regular update of HWs through training and availing IP guidelines is needed from the health system managers.

Having chronic illnesses among HWs was positively associated with IP practices of HWs. HWs who had chronic illnesses were twice to have good IP practice than HWs who had no history of chronic illnesses. This is linked to the nature of COVID-19 and fears that people with chronic illnesses (DM, hypertension, cardiac problems, renal failure, respiratory problems and others). People with such health problems have been identified as the highest risk groups to acquire COVID-19 and become seriously ill from the infection including loss of life than other people $[5-8,11,22]$. Thus, HWs with such health problems would implement all preventive strategies not to get the infection compared to other HWs.

Furthermore, the shortage of PPE and high workload were negatively associated with the IP practice of HWS $(\mathrm{AOR}=0.42,95 \% \mathrm{CI}=0.32-0.74$, and $\mathrm{AOR}=0.40,95 \% \mathrm{CI}$ $=0.36-0.87)$, respectively. The study findings from former studies supported these associations [13, 15, 16, 18, 26]. If there is no access to PPE among HWs, they will not practice IP even if they have adequate knowledge and attitude about IP. In addition to the shortage of PPE, HWs may not apply IP strategies and use PPE properly if they are busy and overloaded with tasks.

\section{Limitation of the study}

Although this study has a wide area coverage, the second largest region in Ethiopia, it has some limitations that might have minimal impact on the study findings and external validity. It was based on online data collection techniques using email and telegram. Some of the health workers might not have access to such services due to limited access to technology, internet service and electric power. Thus, they might not be sampled even if they are important to this study. Also, this study included HWs working only in government health facilities. These might have some limitations in the external validity of the research findings while considering the whole HWs found in the region. Since it is a one-time study, it shared the limitations of a cross-sectional study to establish cause-effect relationships.

\section{Conclusion}

In conclusion, the majority of HWs in the Amhara Region had good knowledge of COVID-19 despite limited prevention practices during the outbreak. Lower age, rural residence, access to training in IP, work with IP guidelines and using social media as information sources were statistically significant factors of HWs' knowledge about COVID-19. Whereas, rural residence, facility type, presence of IP training and guidelines, knowledge about COVID-19, having chronic illnesses, lack of PPE and high workload were significant factors associated with the IP practice of HWs. Thus, a consistent supply of PPE and improving health workers' knowledge through training, and making IP guidelines and information sources available are crucial to prevent COVID-19 infection. Also, managing chronic illnesses and balancing the workloads are required to reduce the risk of acquiring COVID-19 infection.

\section{Supplementary information}

Supplementary information accompanies this paper at https://doi.org/10. 1186/s41182-020-00254-3.

Additional file 1. Information sheet, Statement of Consent,

Questionnaire

Abbreviations

AOR: Adjusted odds ratio; Cl: Confidence interval; COR: Crude odds ratio; COVID-19: Coronavirus Disease 2019; HCs: Health centers; HWs: Health workers; IP: Infection prevention; PPE: Personal Protective Equipment 


\section{Acknowledgements}

The author would like to forward heartfelt thanks to Amhara Regional Health Bureau and health workers who participated in the study and senior researchers for their candid supports during data collection and manuscript write up.

\section{Author's contributions}

The author performed each activity of the manuscript from comencement to final approval with the consultation of senior researchers in the field. Lastly, the author read and approved the final manuscript.

\section{Author's information}

Associate professor of Public Health in the School of Public Health, College of Medicine and Health Sciences, Bahir Dar University, Bahir Dar, Ethiopia. Email: muler.hi@gmail.com or Mulusew.Andualem@bdu.edu.et URL: https://www.bdu.edu.et Or https://bdu.edu.et/cmhs/content/schoolpublic-health-staff

\section{Funding}

No funding was received for this work.

\section{Availability of data and materials}

The datasets analyzed during the current study are available from the corresponding author on reasonable request.

\section{Ethics approval and consent to participate:}

The study was conducted according to the principles of the Declaration of Helsinki and fulfilled the Ethiopian National Health Research and Ethics Guideline. Data were collected after getting written informed consent from each health worker. Participation was fully voluntary based including not responding after reading the instructions and questions. Data confidentiality was maintained through anonymity by avoiding any personal identifiers. Since data collection was online through login, the process was secured.

\section{Consent for publication}

Not applicable

\section{Competing interests}

The author declares as there are no competing interests in this work.

Received: 29 June 2020 Accepted: 29 July 2020

Published online: 20 August 2020

\section{References}

1. Eurosurveillance EETJ: Note from the editors: World Health Organization declares novel coronavirus (2019-nCoV) sixth public health emergency of international concern. 2020, 25(5):200131e

2. Wu YC, Chen CS, Chan YJ. The outbreak of COVID-19: an overview. J Chin Med Assoc. 2020;83(3):217.

3. WHO: Coronavirus disease 2019 (COVID-19) Situation Report -51. Geneva: WHO. (2020). Available online at: www.who.int/emergencies/diseases/novelcoronavirus-2019/situation-reports (accessed June 18, 2020). 2020.

4. Zhou P, Yang X L, Wang X G, Hu B, Zhang L, Zhang W et.al. A pneumonia outbreak associated with a new coronavirus of probable bat origin. Nature. 2020; 579(7798):270 -273

5. Li Q, Guan X, Wu P, Wang X, Zhou L, Tong Y, et al. Early transmission dynamics inWuhan, China, of novel coronavirus-infected pneumonia. Engl J Med. 2020;182:1199-207. https://doi.org/10.1056/NEJMoa2001316.

6. Chan JF-W, Yuan S, Kok KH, To KK-W, Chu H, Yang J, et al. A familial cluster of pneumonia associated with the 2019 novel coronavirus indicating person-to-person transmission: a study of a family cluster. Lancet. 2020; 395(10223):514-23.

7. Yin Y, Wunderink RG. MERS, SARS and other coronaviruses as causes of pneumonia. Respirology. 2018;23(2):130-7.

8. Chan JF-W, Lau SK-P, Woo PC. The emerging novel Middle East respiratory syndrome coronavirus: the "knowns" and "unknowns". J Formos Med Assoc. 2013;112(7):372-81.

9. Wang D, Hu B, Hu C, Zhu F, Liu X, Zhang J et.al. Clinical characteristics of 138 hospitalized patients with 2019 novel coronavirus-infected pneumonia in Wuhan, China JAMA 2020; 323(11):1061-1069.
10. WHO. Coronavirus disease (COVID-19) outbreak: rights, roles and responsiblities of health workers, inclusing key considerations for occupational safety and health. 2020: https://www.who.int/docs/defaultsource/coronaviruse/who-rights-roles-respon-hw-covid-19.pdf?sfvrsn= bcabd401_400.

11. Huang C, Wang Y, Li X, Ren L, Zhao J, Hu Y, et al. Clinical features of patients infected with 2019 novel coronavirus in Wuhan, China. Lancet. 2020;395(10223):497-506.

12. Liu Q, Luo D, Haase J, Guo Q, Wang X, Liu S, et al. The experiences of health-care providers during the COVID-19 crisis in China: a qualitative studyLancet Global Health; 2020.

13. Osseni IA. COVID-19 pandemic in sub-Saharan Africa: preparedness, response, and hidden potentials. Trop Med Health. 2020:48(1):1-3.

14. European Centre for Disease Prevention and Control: COVID-19 situation update worldwide, as of 26 June 2020. https://www.ecdc.europa.eu/en/ geographical-distribution-2019-ncov-cases. 2020

15. Olum R, Chekwech G, Wekha G, Nassozi DR, Bongomin F. Coronavirus Disease-2019: Knowledge, Attitude, and Practices of Health Care Workers at Makerere University Teaching Hospitals, Uganda. Front Public Health. 2020:8:181.

16. Ayinde $\mathrm{O}$, Usman AB, Aduroja P, Gbolahan A. A cross-sectional study on Oyo state health care workers knowledge, attitude and practice regarding corona virus disease 2019 (COVID-19); 2020

17. World Health Organization. WHO coronavirus disease (COVID-19) dashboard World Health Organization, Geneva, Switzerland. https://covid19.who.int/. Accessed 5 May 2020

18. Wang J, Zhou M, Liu F. Reasons for healthcare workers becoming infected with novel coronavirus disease 2019 (COVID-19) in China. J Hosp Infect. 2020;6:1051

19. Centers for Disease Control and Prevention. Centers for Disease Control and Prevention Coronavirus disease 2019 (COVID-19) 2020. https://www.cdc. gov/coronavirus/2019-ncov/cases-updates/cases-in-us.html.

20. Kumar J, Katto MS, Siddiqui AA, Sahito B, Jamil M, Rasheed N, et al. cureus. 2020;12(4):e7737. https://doi.org/10.7759/cureus.7737.

21. Jemal S, Zeleke M, Tezera S, Hailu S, Abdosh A, Biya M, et al. Health care workers' knowledge, attitude and practice towards infection prevention in Dubti referral hospital, Dubti, north East Ethiopia. Int J Infect Dis Therapy. 2019;3(4):66.

22. Sahin AR, Erdogan A, Agaoglu PM, Dineri Y, Cakirci AY, Senel ME, et al. 2019 novel coronavirus (COVID-19) outbreak: a review of the current literature. EJMO. 2020:4(1):1-7.

23. World Health Organization. Infection prevention and control during health care when novel coronavirus ( $\mathrm{nCoV}$ ) infection is suspected: interim guidance, 25 January 2020

24. Zenbaba D, Sahiledengle B, Bogale D. Practices of healthcare workers regarding infection prevention in bale zone hospitals. Southeast Ethiopia Advances in Public Health. 2020;1:2020.

25. Yazie TD, Sharew GB, Abebe W. Knowledge, attitude, and practice of healthcare professionals regarding infection prevention at Gondar University referral hospital, Northwest Ethiopia: a cross-sectional study. BMC Res Notes. 2019;12(1):563

26. Sahiledengle B, Gebresilassie A, Getahun T, Hiko DJ. Infection prevention practices and associated factors among healthcare workers in governmental healthcare facilities in Addis Ababa. Ethiop J Health Sci. 2018;28(2):177-86.

27. Amhara Regional Health Bureau. Regional health bureau annual performance report; 2018.

28. Stat Trek Random Number Generator. https://stattrek.com/statistics/randomnumber-generator.aspx.

29. CDC AFrica: Coronavirus disease 2019 (COVID-19) latest updates on the COVID-19 crisis from Africa CDC. https://www.Africacdc.org. 2020.

30. Saqlain M, Munir MM, Rehman SU, Gulzar A, Naz S, Ahmed Z, et al. Knowledge, attitude, practice and perceived barriers among healthcare workers regarding COVID-19: a crosssectional survey from Pakistan. J Hosp Infect. 2020:105 419e423.

31. Xu K, Lai X, Zheng L. Suggestions on the prevention of COVID-19 for health care workers in department of otorhinolaryngology head and neck surgery. World Journal Of Otorhinolaryngology-Head And Neck Surgery. 2020;2

32. Gezie H, Leta E, Admasu F, Gedamu S, Dires A, Goshiye D. Health care workers knowledge, attitude and practice towards hospital acquired infection prevention at Dessie referral hospital. Northeast Ethiopia. 
33. Gulilat K, Tiruneh G. Assessment of knowledge, attitude and practice of health care workers on infection prevention in health institution Bahir Dar city administration. Sci J Public Health. 2014;2(5):384-93.

34. Desta M, Ayenew T, Sitotaw N, Tegegne N, Dires M, Getie M. Knowledge, practice and associated factors of infection prevention among healthcare workers in Debre Markos referral hospital, Northwest Ethiopia. BMC Health Serv Res 2018;18(1):1-0.

35. Zhou M, Tang F, Wang Y, Nie H, Zhang L, You G, et al. Knowledge, attitude and practice regarding COVID-19 among health care workers in Henan, China. J Hosp Infect. 2020.

36. Zhong BL, Luo W, Li HM, Zhang QQ, Liu XG, Li WT, et al. Knowledge, attitudes, and practices towards COVID-19 among Chinese residents during the rapid rise period of the COVID-19 outbreak: a quick online crosssectional survey. Int J Biol Sci. 2020;16(10):1745.

37. Clements JM. Knowledge and behaviors toward COVID-19 among US residents during the early days of the pandemic: cross-sectional online questionnaire. JMIR Public Health Surveill. 2020;6(2):e19161.

38. Asemahagn MA, Alene GD, Yimer SA. Geographic accessibility, readiness, and barriers of health facilities to offer tuberculosis services in east Gojjam zone, Ethiopia: a convergent parallel design. Res Rep Trop Med. 2020;11:3.

39. Asemahagn MA. The functionality status and challenges of electronic health management information system: the case of public health centres in Amhara region, Ethiopia. Cogent Medicine. 2018;5(1):1437672.

40. Bhagavathula AS, Aldhaleei WA, Rahmani J, Mahabadi MA, Bandari DK Novel coronavirus (COVID-19) knowledge and perceptions: a survey on healthcare workers. MedRxiv. 2020;1.

41. Hussein S, Estifanos W, Melese E, Moga F. Knowledge, attitude and practice of infection prevention measures among health care workers in wolaitta Sodo Otona teaching and referral hospital. J Nurs Care. 2017;6(416):2167-1168.

42. Cooper S, Wiyeh A, Schmidt BM, Wiysonge CS. Cochrane corner: factors that influence compliance by healthcare workers with infection prevention and control guidelines for COVID-19 and other respiratory infections. Pan African Med J. 2020;6:35(23)

43. Shahriarirad R, Khodamoradi Z, Erfani A, Hosseinpour H, Ranjbar K, Emami Y, et al. Epidemiological and clinical features of 2019 novel coronavirus diseases (COVID-19) in the south of Iran. BMC Infect Dis. 2020;20(1):1-2.

\section{Publisher's Note}

Springer Nature remains neutral with regard to jurisdictional claims in published maps and institutional affiliations.

Ready to submit your research? Choose BMC and benefit from:

- fast, convenient online submission

- thorough peer review by experienced researchers in your field

- rapid publication on acceptance

- support for research data, including large and complex data types

- gold Open Access which fosters wider collaboration and increased citations

- maximum visibility for your research: over $100 \mathrm{M}$ website views per year

At $\mathrm{BMC}$, research is always in progress.

Learn more biomedcentral.com/submissions 